\title{
A realidade da educação de surdos no cenário Pandêmico em duas escolas públicas
}

\section{da rede estadual de Guaraí}

\author{
The reality of deaf education in the Pandemic scenario in two public schools of the Guaraí state
} network

La realidad de la educación para sordos en el escenario de Pandemia en dos escuelas públicas de la red del estado Guaraí

\section{Resumo}

A educação de surdos tem um vasto histórico de lutas, desvalorização e desigualdades, mas também de muitas conquistas. O presente trabalho aborda a realidade da educação de surdos no decorrer da pandemia. Apontando como se deu esse processo de ensino aprendizagem de alunos surdos ou deficiente auditivo, com a utilização de vídeo aulas como meio principal de interação professor/aluno. Tendo como objetivo geral, analisar a realidade da educação de surdos ou deficiente auditivo no cenário da pandemia em duas escolas públicas da rede estadual de Guaraí. Foi utilizada como metodologia a pesquisa quali-quantitativa, realizando a coleta de dados através de questionário, destinado aos professores regentes da sala regular de ensino e os intérpretes das escolas alvos da pesquisa. As aulas ocorreram principalmente através de vídeos que foram disponibilizadas para os discentes surdos e ouvintes em plataformas online. É importante que ocorra a inclusão dos alunos surdos na sala regular de ensino, mas não se pode confundir inclusão com integração. O bilinguismo se mostra eficaz no processo ensino aprendizagem dos alunos surdos ou com deficiência auditiva por meio da realização de metodologias ativas para um melhor rendimento escolar.

Palavras-chave: Educação; Inclusão; Pandemia; Deficiência auditiva.

\begin{abstract}
Deaf education has a vast history of struggles, devaluation and inequalities, but also of many achievements. This work addresses the reality of deaf education during the pandemic. Pointing out how this process of teaching-learning of deaf or hearing impaired students took place, with the use of video classes as the main means of teacher/student interaction. The general objective is to analyze the reality of education for deaf or hearing impaired people in the pandemic scenario in two public schools in the state network of Guaraí. Quali-quantitative research was used as a methodology, collecting data through a questionnaire, aimed at teachers in the regular teaching room and interpreters at the schools targeted by the research. The classes took place mainly through videos that were made available to deaf and hearing students on online platforms. It is important that deaf students are included in the regular classroom, but inclusion cannot be confused with integration. Bilingualism is effective in the teaching-learning process of deaf or hearingimpaired students through active methodologies for better academic performance.
\end{abstract}

Keywords: Education; Inclusion; Pandemic; Hearing deficiency.

\section{Resumen}

La educación para sordos tiene una vasta historia de luchas, devaluaciones y desigualdades, pero también de muchos logros. Este trabajo aborda la realidad de la educación de los sordos durante la pandemia. Señalar cómo se desarrolló este proceso de enseñanza-aprendizaje de alumnos sordos o con discapacidad auditiva, con el uso de las videoclases como principal medio de interacción profesor / alumno. El objetivo general es analizar la realidad de la educación para personas sordas o con discapacidad auditiva en el escenario pandémico en dos escuelas públicas de la red estatal de Guaraí. Se utilizó como metodología la investigación cuali-cuantitativa, recolectando datos a través de un cuestionario, dirigido a docentes en el aula regular de docencia e intérpretes en las escuelas objetivo de la investigación. Las clases 
se llevaron a cabo principalmente a través de videos que se pusieron a disposición de los estudiantes sordos y oyentes en plataformas en línea. Es importante que los estudiantes sordos estén incluidos en el aula regular, pero la inclusión no se puede confundir con la integración. El bilingüismo es efectivo en el proceso de enseñanza-aprendizaje de estudiantes sordos o con discapacidad auditiva a través de metodologías activas para un mejor desempeño académico.

Palabras clave: Educación; Inclusión; Pandemia; Pérdida de audición.

\section{Introdução}

Com o surto pandêmico provocado pelo novo coronavírus SARS-CoV-2, diversas atividades rotineiras tiveram que ser paralisadas emergencialmente como medida preventiva de contaminação e disseminação da Covid-19, inclusive a educação (WHO, 2020). Dessa forma foi necessário reinventar alternativas que atendessem a todos com educação de qualidade, de forma igualitária e assegurando à preservação à saúde pública.

Na Declaração de Salamanca (1994), sobre princípios, políticas e práticas na área das necessidades educativas especiais, no artigo primeiro o reconhecimento a necessidade e a importância de se prover o acesso a educação no ensino regular, para crianças, jovens e adultos que necessita de um atendimento educacional especializado. Independentemente do momento vivido, esses estudantes têm esse direito garantido por lei.

A oferta do ensino remoto agrava ainda mais a exclusão de alunos surdos durante a pandemia e das condições exigidas e requeridas a eles (Shimazaki; Menegassi; Fellini, 2020). Em concordância Simões (2020) afirma que evidentemente os mais atingidos pela medida emergencial para dar continuidade à educação durante a pandemia, as aulas remotas, foram os alunos com deficiência auditiva, que não possuem acesso às tecnologias.

Segundo o censo mais recente do IBGE (2010) 9,7 milhões de brasileiros apresentam algum grau de deficiência auditiva, sendo desse total 501,647 mil em idade escolar de nível fundamental. Apesar de ainda se configurar em um grande desafio implantar programas bilingues e inclusivos, vale ressaltar que tal prática tem amparo legislativo (BRASIL, 2002, 2005, 2015). A carência de conhecimento por parte da sociedade sobre a importância de manter o contato o mais cedo possível com a língua de sinais por crianças com deficiência ou perda auditiva, somada ao desconhecimento social da Libras como de fato uma língua provoca limitações imensuráveis às políticas públicas. Contudo, cabe ao Estado garantir políticas linguísticas de ampliação e proteção da língua brasileira de sinais e consequentemente a seus falantes com surdez (MARTINS et al., 2020).

Sendo assim, a educação de surdos e o ensino remoto se mostram como debates necessários e contínuos, sobretudo quando estão interligados (Shimazaki; Menegassi; Fellini, 2020). Como declaram os autores Nozi e Vitaliano (2012) o ensino escolar deve assegurar a todos os alunos o pleno desenvolvimento social, cognitivo, psicológico e afetivo, formando integralmente indivíduos para executarem suas habilidades e funções no meio social.

Vale ressaltar que, esse público deve aprender de forma interligada a língua brasileira de sinais e a língua portuguesa na modalidade escrita, para que haja uma boa compreensão sobre dois tipos de língua e a inclusão dos mesmos da sala de aula do ensino regular e consequentemente para que assim ocorra uma maior interação entre os ouvintes e os surdos ou deficientes auditivos. Morais e Martins (2020) pontuam que o ensino bilíngue, por meio da língua de sinais e do português escrito, deve proporcionar um ambiente linguístico que conduza a aprendizagem da linguagem de forma espontânea favorecida por ambientes em que haja um contexto de significativo de conhecimento. Nesse contexto o presente trabalho possui como objetos específicos: examinar o processo de ensino aprendizagem dos alunos surdos de ou deficientes auditivos; analisar a aplicabilidade da didática da língua de sinais na atuação dos professores; e discutir as principais dificuldades encontradas pelos regentes das escolas.

Para a comunidade surda, a tradução para Libras, é uma das escassas e viáveis ferramentas de acesso linguístico para obtenção de informações. Martins et al (2020) identifica três principais questões preocupantes acerca do isolamento social de crianças surdas: 1) a escassez de interlocutores potenciais em Libras, nesse momento de limitações comunicativas e suas 
consequências para a apropriação da língua de sinais; 2) a desinformação frente aos desafios linguísticos entre pais e filhos surdos; e 3) a falta de recursos e ferramentas de entretenimento em língua de sinais voltadas para crianças surdas.

Uma educação alicerçada nos fundamentos da inclusão que possibilita o aprendizado e respeito pela diversidade, evidenciando que todos os educandos são capazes de construir conhecimento, autonomia e condutas em relação aos valores que são formados socialmente, e que consequentemente beneficiará práticas sociais e integração entre todos os envolvidos (Alves et al., 2013). Em suas pesquisas, Conceição e Martins (2019) perceberam que a maioria dos surdos matriculados em escolas regulares eram filhos de pais não surdos e que não dominavam o uso de Libras ou não a utilizavam nas relações familiares cotidianas, anteriormente à entrada dos filhos em escolas com programas bilíngues. Com isso, fez-se necessário saber se os estudantes surdos ou com deficiência auditiva estão sendo incluídos ou somente integrados na sala regular de ensino, se estão sendo atendidos de acordo com os seus direitos em tempos de aulas remotas.

Diante dos estudos realizados, esta pesquisa justifica-se pela necessidade de um ensino de qualidade fundamentado nas relações humanas não preconceituosas e sem julgamentos à determinadas condições humanas, pois, todas as crianças são iguais, e têm os mesmos direitos, o que vai diferenciá-las e a forma que cada um aprende, respeitando assim, suas peculiaridades e especificidades, de acordo com o seu desenvolvimento intelectual. Diante das possíveis dificuldades encontradas no ensino e na aprendizagem de alunos surdos ou deficientes auditivos, nesse período de pandemia da Covid 19, o estudo foi assim desenvolvido, norteado em analisar a realidade da educação de surdos ou pessoas com deficiência auditiva no cenário da pandemia em duas escolas públicas da rede estadual do município de Guaraí, TO.

\section{Metodologia}

O presente trabalho foi realizado com os professores que atuam e/ou atuavam nas escolas no período de pandemia, em duas escolas públicas Estaduais de Guaraí-TO. A pesquisa é de caráter quali-quantitativa, sendo que as pesquisas qualitativa e quantitativa se complementam, uma pode ser apoiada pela outra, podendo assim aproveitar a quantificação dos dados e ainda uma análise descritiva (Schneider et al., 2017). Podendo assim beneficiar-se dos dois métodos de pesquisa.

A coleta de dados foi obtida através de questionários on-line, com perguntas abertas e fechadas, direcionados a professores da sala regular de ensino e as intérpretes responsáveis pelo acompanhamento desses estudantes surdos ou deficientes auditivos. Com base nisso é possível fazer uma análise de como é a atuação desses profissionais no período de pandemia da Covid-19 voltada para o atendimento do público com surdez. Os dados foram apresentados através da análise quantitativa e descritiva, de forma a demonstrar os processos e técnicas, demostrando como ocorre o processo de ensino aprendizagem dos alunos surdos nessas duas escolas estaduais de Guaraí-TO.

\section{Resultados e Discussão}

Com o intuito de conhecer as práticas pedagógicas e metodologias utilizadas no ensino dos alunos surdos e deficientes auditivos, realizou-se a pesquisa, na qual possibilitou conhecer como ocorreu esse progresso no período da pandemia com aulas online. A pesquisa foi realizada em duas escolas, na qual foram aqui intituladas "escola A e escola B". Foram analisadas as respostas de um questionário com os professores da sala regular de ensino e a professora intérprete das respectivas salas, na qual o aluno surdo ou deficiente auditivo está inserido. O surdo é caracterizado como perda total da audição, enquanto o deficiente auditivo, são caracterizados por perdas parciais da audição, podendo chegar até a perda total, mas geralmente ouvem ou já conseguiram ouvir.

Em relação as respostas dos questionados, quanto a formação do docente? $100 \%$ dos professores são graduados na área que atuam tanto da escola A como da escola B, sendo que a professora(or) de geografia possui um curso de capacitação voltada para o aluno surdo ou deficiente auditivo. Dos professores somente $10 \%$ atuam na área específica de estudo que são os tradutores de intérprete. Isso demonstram que tanto a unidade de ensino A como a B, a maioria dos professores não tem o 
mínimo de conhecimento na área para proporcionar o aluno alvo da pesquisa um processo de ensino aprendizagem básico e significativo, isso representa um fator relevante para a educação desse estudante, visto que esses profissionais precisam saber se interagir e propor metodologias visuais para facilitar o conhecimento do discente. (...) como medida para garantir a formação de profissionais capacitados para atender os surdos o decreto 5.626 de 2005 garante o uso da LIBRAS na educação do surdo desde a educação infantil até a superior, o ensino da Língua portuguesa como segunda língua, o tradutor e o intérprete de LIBRAS- Língua Portuguesa, o professor bilíngue e o instrutor de LIBRAS (Arantes \& Pires 2012).

Quadro 1. Durante esse tempo de regência, você já fez algum curso de capacitação para auxiliar nesse processo de ensino e aprendizagem do aluno surdo? Se não gostaria de fazer?

\begin{tabular}{|c|c|c|}
\hline \multirow[b]{2}{*}{ Disciplinas } & \multicolumn{2}{|c|}{ Capacitação } \\
\hline & Escola A & Escola B \\
\hline $\begin{array}{l}\text { Língua } \\
\text { Portuguesa }\end{array}$ & $\begin{array}{l}\text { Não fez curso de capacitação, mas gostaria de fazer, mas } \\
\text { gostaria de fazer "porque sinto me insuficiente para o } \\
\text { aluno". }\end{array}$ & $\begin{array}{l}\text { Não fez curso de capacitação, mas gostaria de fazer "somente cursos } \\
\text { incompletos", mas gostaria de fazer, "acredito que se cada } \\
\text { profissional tivesse uma especialização adequada haveria uma } \\
\text { melhora muito grande com os de necessidades especiais". }\end{array}$ \\
\hline Matemática & $\begin{array}{l}\text { Não fez curso de capacitação mas gostaria de fazer "É uma } \\
\text { forma de ajudar mais esses alunos". }\end{array}$ & $\begin{array}{l}\text { Não fez curso de capacitação, mas gostaria de fazer "pois nas } \\
\text { situações como a pandemia nos dá uma noção de como trabalhar } \\
\text { com os alunos que precisam de um atendimento especial". }\end{array}$ \\
\hline Ciências & IIIIIIIII & Não fez curso de capacitação e "Não" gostaria de fazer. \\
\hline História & $\begin{array}{l}\text { Não fez curso de capacitação, mas gostaria de fazer, pois “A } \\
\text { necessidade de uma educação plural está na ordem do dia. } \\
\text { Nos professores devemos nos aprimorar constantemente } \\
\text { para reparar esse passado de exclusão". }\end{array}$ & Realizou um curso de capacitação, "Pós-graduação em LIBRAS". \\
\hline Geografia & $\begin{array}{l}\text { Realizou um curso de capacitação "Pedagogia Surda, para } \\
\text { facilitar meu diálogo com eles". }\end{array}$ & $\begin{array}{l}\text { Não fez curso de capacitação, mas gostaria de fazer para "aprender } \\
\text { língua de sinais para facilitar a comunicação". }\end{array}$ \\
\hline $\begin{array}{l}\text { Língua } \\
\text { Inglesa }\end{array}$ & $\begin{array}{l}\text { Não fez curso de capacitação, mas "gostaria de fazer para } \\
\text { atender e compreender melhor o meu aluno com deficiência, } \\
\text { e tentar suprir suas necessidades da melhor maneira } \\
\text { possível. Tanto quanto profissional e social". }\end{array}$ & Não fez curso de capacitação, mas gostaria de fazer "sim". \\
\hline Arte & $\begin{array}{l}\text { Não fez curso de capacitação, mas gostaria de fazer “Com } \\
\text { certeza. Acredito, que nós educadores precisamos nos } \\
\text { qualificar para trabalhar com o aluno especial”. }\end{array}$ & Realizou um curso de capacitação, "Curso noções de Libras". \\
\hline Biologia & $\begin{array}{l}\text { Não fez curso de capacitação, mas gostaria de fazer "para } \\
\text { aprender a comunicar com o discente". }\end{array}$ & I/IIIIII/ \\
\hline Química & $\begin{array}{l}\text { Não fez curso de capacitação, mas gostaria de fazer "Para } \\
\text { facilitar meu diálogo com eles". }\end{array}$ & IIIIIIIII \\
\hline Física & $\begin{array}{c}\text { Não fez curso de capacitação, mas gostaria de fazer pois "É } \\
\text { uma forma de ajudar mais esses alunos". }\end{array}$ & IIIIIIIII \\
\hline $\begin{array}{c}\text { Ensino } \\
\text { Religioso }\end{array}$ & |IIIIIIIIIIIIIIIIIIIIII & $\begin{array}{c}\text { Não fez curso de capacitação, mas gostaria de fazer "sim, porque é } \\
\text { interessante aprender a língua de sinais". }\end{array}$ \\
\hline $\begin{array}{l}\text { Projeto de } \\
\text { vida }\end{array}$ & /IIIIIIIIIIIIIIIIIIII/ & $\begin{array}{c}\text { Não fez curso de capacitação, mas gostaria de fazer "sim, porque é } \\
\text { interessante aprender a língua de sinais". }\end{array}$ \\
\hline $\begin{array}{l}\text { Prof. } \\
\text { intérprete }\end{array}$ & $\begin{array}{l}\text { Realizou um curso de capacitação "cursinhos online e } \\
\text { participei de algumas aulas na Pós em Libras. Cursos mais } \\
\text { avançados e de preferência presenciais em linguagens de } \\
\text { sinais. Pois a Libra está em constante mudança, temos que } \\
\text { está sempre buscando novas metodologias que facilita o } \\
\text { trabalho do professor intérprete". }\end{array}$ & $\begin{array}{l}\text { “Como disse, não fui professora regente, fui intérprete. Fiz e faço } \\
\text { vários cursos sobre Libras, pois está língua está em construção, além } \\
\text { do mais, sempre há algo a aprender que possa facilitar o processo } \\
\text { ensino aprendizagem. Meu aluno era sensacional. Hoje não atuo } \\
\text { mais na escola”. }\end{array}$ \\
\hline
\end{tabular}

Fonte: Autores (2021). 
Quando questionados sobre o tempo de docência, dentre as 19 respostas 14 (82\%) dos professores atuam a mais de 10 anos; 2 (12\%) professores atuam de 2 a 4 anos; e 1(6\%) professor leciona menos de 1 ano na docência; de 5 a 7 anos nenhum dos entrevistados atuo, mais de acordo com a respostas marcadas entre os anos 2 e 4 faz uma ligação por um curto período de tempo. A maioria dos entrevistados leva uma bagagem enorme de experiência na educação, isso significa que já tem conhecimentos sobre diversos assuntos no campo da docência, tanto na prática como na teoria.

O que transparece é que apesar da maioria ter mais de dez anos de docência ainda assim, não possuem capacitações ou cursos preparatórios no ensino especial, para propiciar a inclusão de alunos surdos ou deficientes auditivos. No entanto, passa todos os anos pelas escolas alunos com necessidades diferentes, maneiras diferentes de aprender. No que se refere aos alunos alvos da pesquisa, se não haver um conhecimento específico por parte do docente será um desgaste na relação professor-aluno.

Dos respondentes somente os docentes que ofertam Geografia da escola A, História da escola B, e Arte da escola B, possuem capacitação voltada para o aluno surdo ou deficiente auditivo. É de suma importância o profissional continuar a se capacitar, se atualizando para atender as necessidades dos discentes. Segundo Ferreira et al (2021, p.30018) "o professor da sala comum não pode ficar à par disso, e deve ter uma capacitação adequada para trabalhar com esse aluno". Mesmo que esse docente receba o respaldo do intérprete, ele ainda terá que construir uma relação professor-aluno, e para isso é necessário ter um mínimo de conhecimento voltado para a necessidade do aluno.

Quando não tem intérprete na escola e os professores não são bilíngues necessita da ajuda do intérprete da Libras para intermediar as explicações do professor da sala regular de ensino traduzindo da língua oral para a língua de sinais e vice-versa (Pires \& Arantes, 2012). Isso ressalta a importância da formação continuada para facilitar a comunicação entre o professor e aluno surdo, para que possa aprofundar no assunto e saber lidar com uma cultura diferente e assim desenvolver no aluno surdo competência e habilidades necessárias em prol do desenvolvimento integral.

A lei n 13146/2015 Lei Brasileira da Inclusão (LBI), ressalta no capítulo IV, inciso X - "adoção de práticas pedagógicas inclusivas pelos programas de formação inicial e continuada de professores e oferta de formação continuada para o atendimento educacional especializado" (BRASIL, 2015). Evidenciando a importância desse profissional ter pelo menos o mínimo de conhecimento sobre o assunto, pois se eles não têm conhecimento dessas práticas inclusivas, não será possível realizá-las.

Quadro 2: Há uma inclusão na sala regular de ensino e como ela acontece?

\begin{tabular}{|c|c|c|}
\hline \multicolumn{3}{|c|}{ Inclusão } \\
\hline Disciplinas & Escola A & Escola B \\
\hline $\begin{array}{l}\text { Língua } \\
\text { portuguesa }\end{array}$ & $\begin{array}{l}\text { Sim há inclusão, "Isso facilita a comunicação entre aluno/ } \\
\text { professor regente e entre os colegas". }\end{array}$ & Sim há inclusão, "Por meio de atividades instruídas pelo intérprete". \\
\hline Matemática & Não há inclusão. & Sim há inclusão, "Participando das atividades práticas". \\
\hline Ciências & $/ / / / / / / / /$ & $\begin{array}{c}\text { Sim há inclusão, “A aluna era acompanhada por uma profissional em } \\
\text { Libras, além de acontecer um momento mensal em que a aluna } \\
\text { ensinava a língua de sinais para os colegas “. }\end{array}$ \\
\hline História & $\begin{array}{l}\text { Sim há inclusão, “Lançando mão de material imagético; } \\
\text { tradutor em tempo integral da rotina em sala; realização de } \\
\text { atividades em grupo interagindo com os demais alunos”. }\end{array}$ & $\begin{array}{c}\text { Sim há uma inclusão, "Ele assiste a aula juntamente com os outros } \\
\text { alunos da turma e interage com eles". }\end{array}$ \\
\hline Geografia & Sim há inclusão, "Com auxílio do cuidador”. & $\begin{array}{c}\text { Sim há inclusão, "Através do processo de integração junto aos } \\
\text { demais alunos". }\end{array}$ \\
\hline Língua & Sim há inclusão, "Participam das aulas regulamente & Curso noções de Libras \\
\hline
\end{tabular}




\begin{tabular}{|c|c|c|}
\hline Inglesa & $\begin{array}{l}\text { acompanhados pelos seus cuidadores em sala de aula, é feito } \\
\text { todo um trabalho de interação, juntamente com o cuidador e } \\
\text { o professor regente para que o aluno com deficiência se sinta } \\
\text { o mais acolhido e inserido possível ao meio em que } \\
\text { convive". }\end{array}$ & \\
\hline Arte & $\begin{array}{l}\text { Sim há inclusão, "O aluno está na sala todos os dias, } \\
\text { juntamente com a professora cuidadora". }\end{array}$ & $\begin{array}{l}\text { Sim há inclusão, "Participação nas aulas regulares e } \\
\text { acompanhamento com profissional capacitado". }\end{array}$ \\
\hline Biologia & $\begin{array}{l}\text { Sim há inclusão, "O aluno surdo é acompanhado em sala } \\
\text { para por um cuidador que utiliza a linguagem de sinais". }\end{array}$ & /IIIIIII/ \\
\hline Química & $\begin{array}{l}\text { Sim há inclusão, "com o acompanhamento do professor } \\
\text { auxiliar". }\end{array}$ & |IIIIIIII \\
\hline Física & Não há inclusão & IIIIIIII/ \\
\hline $\begin{array}{c}\text { Ensino } \\
\text { Religioso }\end{array}$ & /IIIIIIIII & $\begin{array}{c}\text { Sim há inclusão, "Ele participa da Sala de Recursos com a } \\
\text { responsável pela tal". }\end{array}$ \\
\hline $\begin{array}{l}\text { Projeto de } \\
\text { Vida }\end{array}$ & /IIIIIIII/ & $\begin{array}{c}\text { Sim há inclusão, "Ele participa da Sala de Recursos com a } \\
\text { responsável pela tal". }\end{array}$ \\
\hline $\begin{array}{c}\text { Prof. } \\
\text { Intérprete }\end{array}$ & $\begin{array}{l}\text { Sim há inclusão, "Os alunos surdos acompanham e } \\
\text { participam de todas as atividades propostas pelos docentes, } \\
\text { independente da disciplina ou conteúdo, mas para facilitar o } \\
\text { trabalho do professor regente é de extrema necessidade o } \\
\text { acompanhamento de um intérprete em Libras". }\end{array}$ & $\begin{array}{l}\text { Sim há inclusão, "Professor cuidador Embora o tempo que atendi o } \\
\text { aluno foi remoto, percebi o esforço da escola em promover ações } \\
\text { voltadas para a participação dos alunos surdos, inclusive utilizando } \\
\text { programas e aplicativos como o Hand Talk". }\end{array}$ \\
\hline
\end{tabular}

Fonte: Autores (2021).

De acordo com os dados expostos no quadro 3 a maioria dos professores aponta que há inclusão, segundo o seu ponto de vista. De acordo com o contexto relatado, observou-se, que o que acontece de fato, é uma integração. Inclusão e integração são termos erroneamente confundidos no meio social, entretanto, é importante ressaltar que possuem significados distintos. A inclusão é voltada para todos os alunos, sem levar em consideração as diferenças e desigualdades que tenham, ou seja, é uma tentativa de igualar a todos pelas distinções e desigualdades (Dalberio et al, 2012). Já a integração é um meio condicional de introdução que depende do aluno, isto é, sua habilidade de adaptação às opções do sistema de ensino, a sua inserção tanto em uma sala de aula regular como uma sala especial, sendo assim, tudo é mantido, não há questionamentos acerca do sistema (Mantoan, 1997). Assim como afirma Dalberio et al, (2012) a integração na escola regular não é direcionada a todos os alunos com necessidades especiais, apenas para aqueles com capacidade de adaptar-se às classes comuns.

Por falta de capacitação para trabalhar a inclusão, grande parte das escolas entendem que basta inserir o aluno surdo na sala regular e passar conteúdos, contudo vale esclarecer que tal ação é insuficiente. Uma alternativa mais favorável é desenvolver metodologias diversificadas para trabalhar a inclusão dos alunos surdos na sala, ocorrendo assim, interação e participação entre ouvintes e alunos surdos ou deficiente auditivo. Para melhor esclarecer essa diferença, Machado (2015), aponta que integrando a criança somente em uma sala regular de ensino, e chamar de inclusão, parece arbitrário, pois ela está somente inserida na sala de aula.

A Lei de Diretrizes e Bases da Educação (LDB) 9394/96 traz no artigo 59, que os sistemas de ensino devem garantir aos alunos com deficiências, o currículo, métodos, técnicas, recursos educativos e organização específicos para atender as necessidades desses alunos. Para melhor atender essas necessidades entende-se que é com a educação bilíngue é a inclusão desses alunos na sala regular de ensino. Pois assim além de haver uma aprendizagem mais interessante e significativa para 
ambas as partes, com interação entre alunos, ambos quebram paradigmas e já se desenvolvem sabendo que cada pessoa tem as suas particularidades, cada pessoa é diferente da outra, e todos merecem respeito.

Proporcionar ao aluno uma educação bilíngue, colabora na construção da aprendizagem. Conforme as Diretrizes da Política Nacional de Educação Especial sobre a educação inclusiva, diz que:

Para o ingresso dos alunos surdos nas escolas comuns, a educação bilíngue - Língua Portuguesa/Libras desenvolve o ensino escolar na Língua Portuguesa e na língua de sinais, o ensino da Língua Portuguesa como segunda língua na modalidade escrita para alunos surdos, os serviços de tradutor/intérprete de Libras e Língua Portuguesa e o ensino da Libras para os demais alunos da escola. (BRASIL, 2001, p.11).

As diretrizes deixam bem claro que a inclusão e uma alfabetização bilíngue andam juntas, no caso do aluno surdo ou deficiente auditivo, a LIBRAS é a primeira língua desse aluno (L1), e o português, de preferência o escrito, será a segunda língua desse aluno (L2).

A Declaração de Salamanca (1994), no item II, de linhas de ação em nível Nacional A. Política e organização, vai declarar no Art. 19 sobre o respeito entre as diferenças e a importância de se trabalhar a língua nacional de signos, ou seja, a língua materna da comunidade surda nas escolas.

Devido ao distanciamento social imposto pela pandemia da Covid-19 os professores da pesquisa estavam fazendo o uso de aulas gravadas com respaldo de atividades impressas, tanto para alunos surdos ou deficientes auditivos como para os demais alunos da sala regular de ensino. Quando questionados sobre o aluno surdo ter acesso a atividades impressas, todos os professores respondam que sim, mas ao detalhar como eram essas atividades, somente o representante do componente curricular Língua Portuguesa da escola A, declara que faz o uso da datilologia. O representante do componente curricular Língua Inglesa da escola B, relata que as vídeo aulas são adaptadas para os alunos com surdez, enquanto os demais deixaram evidente que além do auxílio da cuidadora e da intérprete não havia outra metodologia ou adaptação em suas aulas, de forma a facilitar a aprendizagem desse aluno.

Os métodos ativos voltados para o aluno com deficiência auditiva devem partir da percepção visual, pois na ausência da audição eles vão suprir essa necessidade com a visão. De acordo com Taveira e Rosado (2016), a alfabetização visual é o processo de sistematização, dando um empoderamento dos que conseguem desenvolver as habilidades e técnicas de leitura de imagens, assim desenvolve uma leitura própria. (...) Sendo assim, o uso das metodologias ativas deve ter uma maior relevância no ensino aprendizagem dos alunos, principalmente aos alunos surdos, para ambos se tornarem sujeitos críticos do seu próprio conhecimento (Vale \& Braga, 2020). Ainda temos os recursos visuais que se utilizado com alunos surdos, pode fazer com que ele tenha uma melhor compreensão e entenda essa relação do movimento utilizado para representar o que se deseja expressar.

As intérpretes da escola $\mathrm{A}$ e da escola $\mathrm{B}$, relatam que as atividades eram iguais às dos demais colegas, pois eles (os surdos ou deficiente auditivo) são plenamente capazes de aprender a língua portuguesa. A intérprete da escola B, ainda ressalta que “a Libras é ensinada na Sala de Recursos Multifuncional. No caso o aluno é bilíngue, sendo a Libras sua primeira língua e o Português a segunda”. É importante ressaltar que se houvesse essa educação bilíngue na sala regular de ensino esse aluno teria melhores resultados no processo ensino aprendizagem. A Educação Bilíngue está sendo um método mais adequado para o ensino aprendizado de alunos surdos, sendo que a língua brasileira de sinais - Libras e a língua portuguesa na modalidade escrita, sejam trabalhadas de forma agregada sem distinção de línguas (SANTOS, 2021).

No que se refere como estava acontecendo o processo de ensino remotamente, 9 (53\%) docentes respondem que a aula remota e com os demais colegas, á 4 (24\%) respondem que a aula e feita só com o aluno surdo, 2 (12\%) as aulas e gravada e adaptadas para o aluno em estudo e $2(12 \%)$ as aulas são disponibilizadas para toda turma e nenhum faz atividades impressa fazendo o uso a datilologia. 
Quando questionados se as atividades impressas, todos os professores responderam, tanto da escola A como da B, que o aluno surdo teve acesso, mas não houve nenhuma modificação, eram atividades disponibilizadas para toda turma. Quando questionados sobre o uso da datilologia ou a gesticulação manual, quase todos responderam que não fazem uso, as atividades impressas não são adaptando a linguagem do aluno surdo ou deficiente auditivo.

Essa adaptação nas atividades dos alunos surdos ou deficientes auditivos é de suma importância, facilita o processo ensino aprendizagem desse aluno. “(...) a Datilologia ou alfabeto manual é um sistema de representação, quer simbólica, quer icônica, das letras dos alfabetos das línguas orais escritas, por meio das mãos” (Fernandes \& Romeiro, p.172, 2016). Fazendo uso da datilologia ou gesticulação manual na sala regular de ensino, o professor regente fornece os suportes necessários para que esse aluno consiga desenvolver uma comunicação com os ouvintes.

Quadro 3: Ao fazer o planejamento para aulas remotas, que métodos ou práticas de ensino você utiliza no processo de ensino e aprendizagem dos alunos surdos ou com necessidades auditivas?

\begin{tabular}{|c|c|c|}
\hline & \multicolumn{2}{|c|}{ Planejamento } \\
\hline Disciplinas & Escola A & Escola B \\
\hline $\begin{array}{c}\text { Língua } \\
\text { Portuguesa }\end{array}$ & Não & Desenhos relacionados aos livros e atividades concretas. \\
\hline Matemática & Os mesmos dos outros. & Não. \\
\hline Ciências & IIIIIIIIII & $\begin{array}{l}\text { O planejamento de acompanhamento fica com a } \\
\text { professora cuidadora. }\end{array}$ \\
\hline História & $\begin{array}{l}\text { Por se tratar de um tipo de prática relativamente recente, agravado } \\
\text { ainda pelo período pandêmico. As estratégias no geral passam pelo } \\
\text { uso das redes sociais e aulas gravadas. }\end{array}$ & "Imagens e gestos" \\
\hline Geografia & Pedagogia surda & ilustrações \\
\hline $\begin{array}{l}\text { Língua } \\
\text { Inglesa }\end{array}$ & $\begin{array}{l}\text { As atividades são adaptadas para cada tipo de deficiência. Após, } \\
\text { encaminhada ao coordenador da sala de recursos, que faz uma análise } \\
\text { das atividades para depois enviar ao aluno. }\end{array}$ & $\begin{array}{l}\text { A mesma metodologia que e trabalhada com os demais } \\
\text { alunos do ensino regular. }\end{array}$ \\
\hline Arte & $\begin{array}{l}\text { "Não utilizei nenhum método diferente, pois os educandos estavam } \\
\text { sendo assistidos pelo professor cuidador". }\end{array}$ & $\begin{array}{c}\text { "Nenhum, somente planejamento para alunos sem } \\
\text { necessidades." }\end{array}$ \\
\hline Biologia & $\begin{array}{l}\text { "Foi um período muito conturbado, por falta de material didático e } \\
\text { plataforma digitais disponíveis. O que foi possível fazer, foi o repasse } \\
\text { de todo o material e conteúdos ao professor cuidador para que ele } \\
\text { pudesse orientar o aluno". }\end{array}$ & /IIIIIII/ \\
\hline Química & “Através do cuidador”. & IIIIIIIII \\
\hline Física & “Através do cuidador". & IIIIIIIII \\
\hline $\begin{array}{c}\text { Ensino } \\
\text { Religioso }\end{array}$ & IIIIIIIIII & "Não utilizo, ele acompanha por igual com os demais". \\
\hline $\begin{array}{l}\text { Projeto de } \\
\text { vida }\end{array}$ & /IIIIIIII & "Não utilizo, ele acompanha por igual com os demais". \\
\hline $\begin{array}{l}\text { Prof. } \\
\text { intérprete }\end{array}$ & $\begin{array}{l}\text { "Vídeo gravados por mim com a explicação do conteúdo. Pesquisas } \\
\text { no Youtube com vídeo aulas em libras e legendado". }\end{array}$ & $\begin{array}{l}\text { "As aulas são planeadas pelo professor da turma, no meu } \\
\text { caso apenas faço a interpretação das aulas da língua } \\
\text { portuguesa para libras". }\end{array}$ \\
\hline
\end{tabular}

Fonte: Autores (2021). 
É interessante a reflexão das respostas dadas por cada profissional sobre a forma que deveria ser o planejamento dos docentes e quais meios tecnológicos os mesmos estavam buscando para trabalhar com esses alunos envolvendo assim técnicas ou estratégias para facilitar o processo educacional dos alunos denominados ouvintes e o aluno surdo ou deficiente auditivo.

Devido ao atual momento em que se encontra, ainda enfrentando a pandemia da Covid-19, e vivenciando os problemas que ficaram mais aparentes, inclusive na educação, fica evidente a importância da utilização das TDICs no contexto escolar. Torna-se indispensável o uso das tecnologias digitais por parte dos docentes na sua metodologia, com isso o processo de ensino aprendizagem fica mais dinâmico e atrativo (Tavares et al, 2021). O uso das tecnologias digitais esteve mais presente do nunca na vida do professor nesse período pandêmico. As duas intérpretes, tanto da escola A, como da escola B relatam que gostam de usar um aplicativo chamado "Hand Talk", ele tem a função de traduzir palavras ou textos para a língua de sinais. Essa é uma ferramenta muito interessante, não só para usar com esse aluno surdo ou deficiente auditivo, mas com todos da sala regular de ensino. Com a inserção de plataformas digitais nas escolas como metodologias inovadoras, auxilia bastantes na transmissão de conteúdos futuros em tempos de pandemia, pois facilita a comunicação entre os envolvidos na educação de crianças surdas (Martins, et al, 2021).

Quanto aos professores da sala regular de ensino quando questionados se fazem uso de alguma tecnologia, aplicativos para auxiliar no processo ensino aprendizagem desse aluno no decorrer do ensino remoto, observou - se que dentre os 19 pesquisados, 5 (26\%) utilizou ferramentas e aplicativo virtuais para melhorar a comunicação com a turma e entender um pouco a língua de sinais para facilitar a tradução no momento da elaboração das atividades, sendo que 2 (10\%) são os professores intérpretes que fazem o uso de aplicativo virtuais inovadores que auxiliam na elaboração das atividades e das gravações de vídeos aulas e 12 (63\%) afirmam não fazer uso de nenhuma plataforma ou ferramenta pedagógica.

Dentre as respostas dos pesquisados, os professores das disciplinas da escola A, 4 professores das expectativas disciplinas mostraram mais incentivo em relação a procurar meios para tentar melhorar a comunicação entre o aluno alvo, dentre essas são as atividades impressas, eslaides, Meet e WhatsApp e somente 1 foi em buscar de conhecer uma ferramenta diferente, que foi o grupo de estudo. Já as professoras intérpretes que auxiliam os professores das seguintes disciplinas, já tem conhecimento na área e sabem qual e a melhor forma para ajudar os professores então os aplicativos foram Hand Talk, WhatsApp, YouTube, Live transcriber e outros. E os demais que responderam que não faz uso de nenhum aplicativo ou ferramenta pedagógica, isso significa que não foi por falta de estímulo, mais deve ter sido pela correria diária desses profissionais, por não ter somente uma turma para reger ou por curto período de tempo para planejar, sendo assim, pode ter acontecido vários fatores que levaram a maioria dos professores não ter encontrado um meio para melhorar a comunicação vê assim minimizar a situação da falta de interação entre o professor regente e o aluno alvo da pesquisa.

Quadro 4. Quais as dificuldades encontradas no processo de ensino e aprendizagem em aulas remotas para os alunos surdo ou deficientes auditivo?

\begin{tabular}{|c|c|c|}
\hline \multirow{2}{*}{ Disciplinas } & Escola A & \\
\hline $\begin{array}{c}\text { Língua } \\
\text { Portuguesa }\end{array}$ & "As tarefas não adaptadas". & "Muitas, pois não fomos capacitados para receber esse aluno". \\
\hline Matemática & "Não teve formação adequada". & "A minha falta de experiencia para atividades diferenciadas. \\
\hline Ciências & IIIIIIIIII & "Não tive dificuldade o aluno acompanhado pela família". \\
\hline
\end{tabular}


Research, Society and Development, v. 10, n. 15, e302101523360, 2021

(CC BY 4.0) | ISSN 2525-3409 | DOI: http://dx.doi.org/10.33448/rsd-v10i15.23360

\begin{tabular}{|c|c|c|}
\hline História & $\begin{array}{l}\text { "Assim como os demais alunos, a distância dificultou o } \\
\text { processo de ensino e aprendizagem". }\end{array}$ & "Em muitos momentos, a internet". \\
\hline Geografia & $\begin{array}{l}\text { "A falta de convivência foi muito ruim, o não está unto } \\
\text { para tirar as dúvidas". }\end{array}$ & $\begin{array}{l}\text { Conseguir fazer a integração e ministrar de forma diferenciada os } \\
\text { conteúdos através de vídeo aulas com a turma. }\end{array}$ \\
\hline $\begin{array}{l}\text { Língua } \\
\text { Inglesa }\end{array}$ & $\begin{array}{l}\text { "Mesmo as atividades adaptadas para este aluno os pais } \\
\text { sentem dificuldades em orientá-los quando na realização } \\
\text { das mesmas". }\end{array}$ & $\begin{array}{l}\text { "A maior dificuldade é que os professores da rede estadual não possuem } \\
\text { uma especialização adequada para trabalhar de forma diferenciada com } \\
\text { esses alunos". }\end{array}$ \\
\hline Arte & $\begin{array}{l}\text { Não saber como o educando está se sentindo em relação } \\
\text { a esse processo remoto, pois foi muito difícil para todos } \\
\text { os educandos e também para os educadores". }\end{array}$ & "Não sou capacitada para trabalhar com esses alunos". \\
\hline Biologia & $\begin{array}{l}\text { "A falta de equipamentos para a impressão do material } \\
\text { didático para esses alunos (Libras)". }\end{array}$ & /IIIIIIII \\
\hline Química & "Como se comunicar com eles". & $\mid / I I I I I I / I$ \\
\hline Física & "Não ter formação adequada". & I/II/II//I \\
\hline $\begin{array}{c}\text { Ensino } \\
\text { Religioso }\end{array}$ & IIIIIIIII & "Não houve dificuldades". \\
\hline $\begin{array}{l}\text { Projeto de } \\
\text { vida }\end{array}$ & IIIIIIII/ & "Não houve dificuldades". \\
\hline $\begin{array}{l}\text { Prof. } \\
\text { intérprete }\end{array}$ & $\begin{array}{l}\text { "Foram muitas, pois o aprendizado pra eles torna mais } \\
\text { fácil de entender quando o intérprete está lado a lado, } \\
\text { além de uso de sinais, há também a leitura labial, que } \\
\text { facilita muito para o entendimento do aluno surdo. Com } \\
\text { o surgimento da pandemia, tudo isso não era possível". }\end{array}$ & $\begin{array}{l}\text { "Internet precária, nem sempre funcionava a contendo. No mais, embora } \\
\text { tivesse acompanhamento especializado, a presença do intérprete junto ao } \\
\text { professor faz muita diferença no aprendizado do aluno. Algo que não foi } \\
\text { possível durante a pandemia". }\end{array}$ \\
\hline
\end{tabular}

Fonte: Autores (2021).

Os depoimentos apontam algumas barreiras e dificuldades em relação à uma deficiência na formação ou capacitação dos docentes em relação ao aluno surdo ou deficiente auditivo, a falta de socialização entre os alunos e prof essores devido o distanciamento. É compreensível os docentes sentirem dificuldade, pois o distanciamento social foi uma medida emergencial a qual ninguém estava preparado para enfrentar. E quando incluí o aluno surdo ou deficiente auditivo, consequentemente tem a um grau a mais de dificuldade. Na situação em que se encontra há a necessidade de uma formação adequada para que na hora do planejamento, as ações sejam repensadas e passadas com ato de eficiência em prol da educação do aluno surdo ou deficiente auditivo, no entanto, a maioria dos professores regentes não possui nenhum tipo de capacitação voltada para o meio tecnológico, dificultando assim o processo de transmissão de conteúdos (Santos \& Leite 2021).

Pode-se listar tanto fatores externos como internos que impactam e até mesmo interferem no ensino aprendizado, dentre eles estão a falta de formação e capacitação continuada dos profissionais da educação e falta de material didático para os professores, esses e outros fatores que enfraquece e interfere no desenvolvimento intelectual do aluno com deficiência auditiva, pode se notar nas respostas dos profissionais respondentes da pesquisa.

As queixas mais frequentes relatadas na pesquisa foram a respeito da comunicação e da dificuldade em realizar as atividades adequadas aos alunos com deficiência auditiva. São problemas recorrentes na educação, os alunos surdos são 
minorias dentro de uma sala de aula, fazer algo pensando na inclusão desse aluno não é uma tarefa fácil, essa conscientização vai muito além da sala de aula e dos professores e dos alunos surdos ou deficientes auditivos.

\section{Conclusão}

Ao término da pesquisa, conclui - se que o objetivo geral foi alcançado com os dados obtidos foram analisados vários fatores diante das respostas dadas pelos docentes, como a influência da tecnologia e metodologias diversificadas no momento de planejar as aulas, principalmente no cenário atual em que se encontra devido o distanciamento entre o professor e aluno e pontos positivos e negativos que ocorreu durante o processo de ensino aprendizado de alunos ouvintes e alunos surdos ou deficiente auditivo.

O período pandêmico, dificultou bastante a socialização tanto para os docentes como para os discentes e todos que estão envolvidos, para os professores do ensino regular das respectivas escolas, por não ter sido capacitados ou não tiveram uma formação na área sentiu - se insuficientes para prepara um material adequado para esse aluno, com isso, contou se com o apoio da intérprete e coordenadora da educação inclusiva.

Diante das respostas dos professores intérpretes da escola A e B buscou usar tecnologias inovadoras para facilitar a transmissão do conteúdo, ferramentas que pudessem traduzir a língua de sinais para a datilologia. Tendo em vista todos os depoimentos levantados, tanto na escola A como a B, foi possível perceber a falta de formação para os docentes regentes, a falta de políticas públicas para a obtenção de material adaptado, dentre outros fatores internos e externos, sendo assim, como as escolas não opta pelo método do bilinguismo para facilitar o processo educacional dos educandos,

Isto posta surge alguns pontos importantes a educação como a inserção de profissionais especialistas na área atuando como suporte na elaboração dos conteúdos, o trabalho em conjunto com a família do aluno alvo da pesquisa, a busca contínua por meios tecnológicos e principalmente com o apoio das intérpretes os educadores adquiriu um pouco de conhecimento na área através da elaboração de metodologias. Porém, isso representa apenas o início de uma grande conquista no ensino especial remoto, onde pretende-se buscar melhorias para educação de surdos no formato inclusivo.

\section{Referências}

Alves, T. P., Sales, Z. N., Moreira, R. M., de Carvalho Duarte, L., \& Couto, E. S. (2013). Inclusão de alunos com surdez na educação física escolar. Revista Eletrônica de Educação, 7(3), 192-204.

Diretrizes, L. (1996). bases da Educação Nacional.

BRASIL, L. D. D. (2002). Lei n 10.436, de 24 de abril de 2002. Dispõe sobre a Língua Brasileira de Sinais-Libras e dá outras providências. Diário Oficial da União, 23-23.

Silva, C. M. D., \& Silva, D. N. H. (2016). Libras na educação de surdos: o que dizem os profissionais da escola?. Psicologia Escolar e Educacional, 20, 3344.

Abreu, T. P. C. D., Vilardo, M. A. T., \& Ferreira, A. P. (2020). Acesso das pessoas com deficiência mental aos direitos e garantias previstos na Lei Brasileira de Inclusão por meio do Sistema Único de Assistência Social. Saúde em Debate, 43, 190-206.

Salamanca, D. (1994). Princípios, políticas e prática em educação especial. Espanha:[Sn].

Conceição, B. S., \& de Oliveira Martins, V. R. (2019). Discursos de pais de crianças surdas: Educação Infantil e a presença da Libras. Educação, (44), 1-24.

Dalberio, M. C. B., Pereira, H. D. O. S., \& Aquino, O. F. (2012). Inclusão versus integração: a problemática das políticas e da formação docente. Revista iberoamericana de educación.

Fernandes, C. C., \& de Araújo Romeiro, C. (2016). A contribuição da datilologia como estratégia metodológica no processo de alfabetização. Revista diálogos, 4(1), 170-185.

Trindade Ferreira, J., de Figueiredo Corrêa, O., da Silva Costa, J. F., Moreira, C. E. M., de Souza, T. C., Pinheiro, M. D. C. B., ... \& da Costa Barbosa, C. F. (2021). A importância do processo de inclusão na aprendizagem do aluno surdo. Brazilian Journal of Development, 7(3).

IBGE, I. (2010). Instituto Brasileiro de Geografia e Estatística. Censo demográfico.

Machado, E. C. (2015). O surdo na rede regular de ensino: integração X inclusão. Revista Transformar, (7), 88-101. 
Research, Society and Development, v. 10, n. 15, e302101523360, 2021

(CC BY 4.0) | ISSN 2525-3409 | DOI: http://dx.doi.org/10.33448/rsd-v10i15.23360

Mantoan, M. T. E. (1997). Inclusão escolar de deficientes mentais: que formação para professores. A integração de pessoas com deficiência: contribuições para uma reflexão sobre o tema. São Paulo: Memnon, 119-127.

de Oliveira Martins, V. R., NicholsMe, G., Torres, R. C., Bonfim, T. C., Fornari, R. V., Iriarte, A. C. S., ... \& Moreira, J. L. P. (2020, August). Atenção bilíngue virtual para crianças surdas em meio à pandemia do" coronavirus"-covid-19. in Anais do CIET: EnPED: 2020-(Congresso Internacional de Educação e Tecnologias| Encontro de Pesquisadores em Educação a Distância).

Garcia, R. M. C. (2013). Política de educação especial na perspectiva inclusiva e a formação docente no Brasil. Revista Brasileira de Educação, 18, 101-119.

Morais, M. P. D., \& Martins, V. R. D. O. (2020). Educação bilíngue inclusiva para surdos como espaço de resistência1 2. Pro-Posições, 31.

Nozi, G. S., \& Vitaliano, C. R. (2012). Saberes necessários aos professores para promover a inclusão de alunos com necessidades Educacionais Especiais. Revista Educação Especial, 25(43), 333-347.

Santos, R. D. S. (2021). Material didático de Língua Portuguesa para surdos: um olhar sobre a perspectiva de ensino (Master's thesis).

Santos, R. S. D. (2021). Os desafios frente ao atendimento educacional especializado remoto para alunos com surdez em tempo de pandemia no centro Raimundo Nonato Dias Rodrigues.

Schneider, E. M., Fujii, R. A. X., \& Corazza, M. J. (2017). Pesquisas quali-quantitativas: contribuições para a pesquisa em ensino de ciências. Revista Pesquisa Qualitativa, 5(9), 569-584.

Shimazaki, E. M., Menegassi, R. J., \& Fellini, D. G. N. (2020). Ensino remoto para alunos surdos em tempos de pandemia. Práxis Educativa (Brasil), 15.

Simões, R. D. C. D. S. (2020). Educação na pandemia: a realidade do ensino remoto para surdos no município de Pirpirituba/PB (Master's thesis).

Taveira, C. C., \& Rosado, A. (2016). O letramento visual como chave de leitura das práticas pedagógicas e da produção de artefatos no campo da surdez. Revista Pedagógica, 18(39), 174-195. 